\title{
Ocean noise could injure more than mammals
}

\section{Geologists should wait until more is known about the harm their work may do to fish.}

Sir - Your News story "Push to protect whales leaves seafloor research high and dry" (Nature 428, 681; 2004) reports that the Lamont-Doherty Earth Observatory survey of the 65-million-year-old Chicxulub meteorite crater, coordinated by the US National Science Foundation (NSF), was cancelled because of concerns that the airguns used could harm marine mammals.

As a science adviser for Seaflow - a conservationist organization with a mission to reduce harmful underwater noise (see www.seaflow.org) - I am concerned that the only instrument we have to protect the ocean environment resides in legislation protecting marine mammals.

Lamont-Doherty did apply for marine mammal 'incidental harassment authorization', and received authorization from the National Marine Fisheries Service to deploy the airguns under the rules of the US Marine Mammal Protection Act. The Chicxulub survey was ultimately blocked by a Mexican environmental agency that was worried about marine mammals, but I believe that there are other good reasons to refrain from seismic airgun research until we know what effects the blasts have on the marine environment.

What is not included in US law, or even in the discussion, is the impact that airgun explosions have on fish populations.

There is evidence that seismic airguns can damage fish ears (R. D. McCauley et al. J. Acoust. Soc. Am. 113, 638-642; 2003). We also know that fisheries are compromised by airgun operations. The Chicxulub survey was to take place in $3,000 \mathrm{~km}^{2}$ of tropical waters at depths of 50-100 m. To ignore the probable impact that this study would have had on fish populations reveals an added dimension to the shortsightedness of the programme.

Although halting the survey may have been costly in the short term, it may make more sense to spend NSF money looking at the impacts of anthropogenic noise on fish. Once the biological research is more complete, geologists can do their research using methods that will not compromise the biota, raise the ire of fishermen and conservationists, or force action by environmental protection agencies.

Michael Stocker

Seaflow, 1062 Fort Cronchite, Sausalito, California 94965, USA

\section{Edwardian anaesthetists had a finger on the pulse}

Sir - I read with great interest in your 100 Years Ago column (Nature 428, 705; 2004) an excerpt from the 14 April 1904 issue of Nature which addressed the increasing death rates under chloroform anaesthesia. Back then, the American and British schools of anaesthesia had chosen to use different general anaesthetics. The Americans had embraced diethyl ether, with its more forgiving margin of error, allowing administration by physicians, nurses or medical students. The British preferred chloroform, despite its narrower margin of error, which led to more frequent complications (including death) and required a physician to administer it safely. The ongoing controversy in America over whether nurses or physicians should administer anaesthetics is, arguably, left over from this early difference in practice.

The irony is that the 1904 author criticized "the ignorant and careless anaesthetist" for using 'cardiac syncope' (a loss of consciousness or fainting due to the heart not pumping enough blood to the brain) as an excuse following death under chloroform. However, the most likely cause of death in patients who died suddenly under chloroform anaesthesia was - we now know - a ventricular fibrillation or tachycardia, causing the patient to immediately become pulseless and unconscious. So cardiac syncope was probably the correct postmortem diagnosis, even though the physiological basis for the syncope could not have been fully appreciated until decades later.
So how did the anaesthetists of 1904 make such a reasonable diagnosis? Before the introduction of a cuff for measuring blood pressure, and recording it on a written graph, the anaesthetist's left hand customarily held the mask to the patient's face, while his left little finger continuously registered the pulse under the patient's chin. This could be skilfully done, after some training, while maintaining a firm mask-grip. The anaesthetist would therefore know immediately when the pulse faded. Indeed, this manual skill is still useful, whenever our microprocessorcontrolled blood-pressure devices fail during a mask anaesthetic, and we must know the patient's status. We also derive the expression, "to keep one's finger on the pulse", from this anaesthetic technique long predating the Edwardian era.

\section{Francis X. Dillon}

Department of Anesthesia, Indiana University School of Medicine, Fesler Hall Room 204, 1120 South Drive, Indianapolis, Indiana 46202-5115, USA

\section{Supplementary materials need the right format}

Sir - It is becoming increasingly common for articles in top-tier journals to be accompanied by online supplementary text, figures, graphs or other materials. These supplementary materials typically provide either additional evidence for an article's claim or a detailed description of the methods used to carry out the study. Unfortunately, the format in which this material is stored is not always optimal.

Nature's policy is essentially "anything goes", accepting supplementary files in a wide array of formats, and publishing them as provided by the author (see www. nature.com/nature/submit/finalsubmission/ SI/index.html). Nature's preferred format for text, tables and images is the Microsoft Word format (.doc), which seems to be the natural choice, given the widespread use of Microsoft Word by scientists.

Unfortunately, .doc is particularly illsuited for archival and online-publishing purposes. Whether a particular .doc file can be opened and printed successfully depends on the exact version of Microsoft Word installed, the version of the operating system installed, the printer installed, and the fonts installed. Furthermore, the details of the .doc format are secret and change from version to version. As a result, some of Nature's readers will have problems opening and printing supplementary material. Moreover, we should expect that many of these documents will fail to open properly 10 to 20 years from now.

I believe that by allowing publication of .doc files alone, Nature does a disservice both to its authors and to its present and future readers. At the minimum, Nature should convert .doc files into portable document format (.pdf) — which has fully published specifications (see http://partners.adobe.com/asn/tech/pdf/ specifications.jsp) and is suitable for online publishing and archiving - and publish the .pdf files alongside or instead of the .doc files. Similar procedures have been adopted by Science and by the Proceedings of the National Academy of Sciences.

\section{Claus O. Wilke}

Keck Graduate Institute of Applied Life Sciences, 535 Watson Drive, Claremont, California 91711, USA 